\title{
BEYOND THE ZERO WASTE CONCEPT
}

\author{
William Hogland \\ Fabio Kaczala \\ Yahya Jani \\ Marika Hogland \\ Linnaeus University, Sweden \\ Amit Bhatnagar \\ University of Eastern Finland, Finland
}

\begin{abstract}
During the last 40 years the existing solid waste handling system schemes have been developed and implemented including advanced systems for recovery and reuse. However, even though these recycling systems have not been always economically feasible during the entire period, recycling systems have been implemented thanks to the wide support from the citizens and their interest for source separation. There has been a feeling among citizens and even waste management companies that this is a sustainable and nature resources saving way to work. Today "the zero waste concept" is used more and more both in Sweden and other parts of the world discussing different ways of modern waste management in order to reduce the amount of waste for final disposal as much as possible close to zero. The existing challenges in the future include recovery of metals, nutrients, and other valuable constituents that have escaped from the anthropogenic circuits since the industrial. During the next 30 years more focus must be directed towards recovery of lost resources in ore mining waste, old landfills, in harbor and sea sediments, slag, ashes, sludge but also materials that are bound to urban constructions as residential, commercial and industrial infrastructures, water distribution networks, sewage systems and underground electric/electronic networks such as telephone etc. An overview regarding the recovery of mentioned materials and chemical compounds called "Beyond the zero waste concept" will be presented in this paper in order to raise concerns and awareness about the importance of establishing a new model of waste management schemes..
\end{abstract}

\section{KEYWORDS}

Sediment mining, landfill mining, environment, metals, nutrients, toxic substances, chemical bindings, recovery, extraction, economy.

\section{INTRODUCTION}

The zero waste concepts has been used more and more both in Sweden and other parts of the world discussing different ways of to implement new models of waste management. Reduction of the waste going to different ways of final disposal has been encouraged and developed mainly during the last three decades and even though the recovery/reuse/recycling 
is not in many cases economically feasible, these actions have been widely supported by citizens and their interest for source separation. Initially the zero waste philosophy encouraged the idea of redesigning resources life cycles so that all products and materials are reused/recovered and is taken the entire system through the society of man from the source to the end of pipe or from cradle to cradle.

The definition of zero waste commonly used was stated by the Zero Waste International Alliance in 2004 (ZWIA , 2014):

Zero Waste is a goal that is ethical, economical, efficient and visionary, to guide people in changing their lifestyles and practices to emulate sustainable natural cycles, where all discarded materials are designed to become resources for others to use. Zero Waste means designing and managing products and processes to systematically avoid and eliminate the volume and toxicity of waste and materials, conserve and recover all resources, and not burn or bury them. Implementing Zero Waste will eliminate all discharges to land, water or air that are a threat to planetary, human, animal or plant health.

Many industrial and urban activities including households generate considerable amounts of solid waste every day all over the world. Even if the recycling and energy utilization of the solid waste has been done, the waste generation still increases due to population growth. According to Laurent et al. (2014) the annual total solid waste generation worldwide is approximately 17 billion tonnes with a prediction to reach values as high as 27 billion tonnes by 2050 . Solid waste that has been daily discarded by the society contains several important constituents, for example valuable metals such as zinc, copper, nickel, chromium and lead can be found everywhere. At the same time man are wasting huge volumes of important metal resources, scientific literature has recently highlighted the continuous depletion of natural stocks (including metals) resulting in higher prices in the metal market (Meylan and Spoerri, 2014). Not only the prices have become higher in the market, but also according to Boesch et al. (2014) this trend of increasing natural resources prices is expected to be even more pronounced in the near future. Population is growing and today more than $50 \%$ of the world population is living in cities. People are increasing their demand of material things more and more and there can't be seen any new trends showing other ways of living and consumption pattern. Therefore, it is an increased need to supply all inhabitants with commodities in an economically and socially sustainable manner which brings the necessity to shift the traditional linear models followed by our society not only into closed-loop models but also consider the recovery of all valuable resource man have lost as waste products from our daily activities but also through history. There is also a crucial need to look into waste reservoirs (soils, sludge, slag and ash from incineration, bottom sediments, soils from landfills, waste from ore mining etc) that are fully contaminated with metals and nutrients as potential secondary stocks of such valuable constituents. This lead us into the topic of the paper and introduction of the "Beyond the zero waste concept" which encourages recovery of all materials lost during the entire life cycles of different products manufactured, which are still available in different sinks (landfills, sediments of rivers, ocean, etc.). All waste, materials and chemical compounds lost as sludge, slag, harbor sediments and others can in principle, return to the anthropogenic loops and the toxics substances could be removed from the circuits and handle in an environmental friendly way. The long-term goal is to apply such innovative approach in an environmental and economic efficient way, making use of the accumulated knowledge, including reuse/recycling of materials bound in urban and rural structures. This will include landfill mining, glass mining, harbor and bay mining as well as seafloor mining. 
A potential secondary economic source of metals in the waste might be fine-grained fractions of different types of solid material, such as excavated landfills, and dredged bottom sediments from harbors, sludge, and fly ashes from incineration plants. Recent excavations of different landfills in Sweden and Estonia studied by the Environmental Science and Engineering Group (ESEG) at Linnaeus University and Estonian University of Life Science in cooperation with the business sector have shown the potential of fine-grained particles $(<40 \mathrm{~mm})$ to contain a substantial amount of metals. However, there is a big question mark on how to extract such metals from fine-grained fraction in a feasible way in terms of both economic and technical aspects. There is a lack of science-based knowledge regarding adequate ways to implement resource recovery from fine-grained fractions of waste such as landfilled wastes, bottom sediments in harbors etc. This has been recently highlighted by Boesch et al. (2014) which state that whereas energy recovery from waste material has received much attention in the last years and is rather advanced technologically the potential of material recovery from byproducts of waste management processes. Incineration residues has often been neglected from recovery but for scrap however, it is also source of many metals and phosphorous.

Today there is a need to put strong efforts in order to evaluate the potential use of fine-grained fraction $(<40 \mathrm{~mm})$ of landfilled waste, dredged sediments from harbors and from fly ashes as secondary source of valuable metals. There must be collaboration between the academia and the business sector with focus on understanding the main aspects in terms of technology and economy and potential barriers that might null the hypothesis of fine-grained fractions being a potential source of metals. More research studies are needed with focus on the development of a new methodological approach for fine-grained fraction separation, characterization and metals extraction. The development of science-based knowledge in the area must be carried out related to innovative methods that for society are environmentally friendly and economic and transferred them to the business sector in order to solve existing problems. The main idea must be to establish and develop new research and highlight the current needs to consider contaminated materials as a resource rather than a waste to be handled and disposed off.

As soon as an understanding on how valuable metals are distributed in fine-grained fractions and their chemical bindings, separation methods with the ability to separate fractions of interest for further recovery must be developed in order to have an economically feasible process and make it possible to tackle a much smaller volume with high concentrations of metals. According to Bolan et al. (2014), the ability to separate fractions with low contamination from those having high contaminant concentrations varies for different soils due to different origin of contamination (e.g., mining related contaminants that occur in mineral phases versus soil contaminated with chemical spillage where contaminants occur as soluble salts and particle coatings) which makes it necessary to develop methods and perform them in each specific case of excavated waste, fine fractions in bottom sediments and finally fly ashes. Soil washing is one of the widely used techniques consisting of a physical separation process that utilizes water to concentrate contaminants into a smaller soil volume by means of particle size separation, specific-gravity separation, attrition scrubbing, froth flotation or magnetic. However, according to Jensen et al. (2007) soil washing has limited success when dealing with fine fractions due to troublesome handling of such smaller fractions. Furthermore, the authors state the need for an efficient unit that makes the decontamination (extraction) of fine-grained fractions through soil washing towards the beneficial use of the washed material (in this specific case, metals recovery) economically and environmentally feasible. 
Another important aspect that needs to be better understood is that the properties of fine grained fractions might differ substantially and therefore characteristics, particle size distribution and metal concentration is needed in order to increase the economic and technical feasibility of soil washing separation methods. Bound to those fine fractions are also significant amount toxic substances of organic/inorganic character and for instant pharmaceutical which also need to be removed and treated in an adequate way which might be expensive.

Finely graded particles cause major problems in operational aspects in relation to soil/sediment remediation (Andreottola et al 2010), and considering the presence of considerable amounts of fine soil fraction in landfills and the presence of metals, it is of great importance to understand how these constraints can be minimized and a method for extraction can be developed in conjunction with the business sector in order to increase economic benefits through efficiency and effectiveness. According to Zhang et al. (2009), even though various sediment technologies have been tested since the 1990's most of them have been still in experimental and validation stages emphasizing the needs to investigate and develop proper methods to combine remediation and metal recovery from fine graded waste to be applied in real conditions. Furthermore, Vandevivere et al. (2001) has stated that efficiency and time required washing and extracting metals from real polluted soils and sediments were longer than the ones required when studying artificially polluted solid matrixes highlighting the importance of carrying out research dealing with real problems and real polluted media.

The Zero Waste concept was initially introduced as a way to reduce the amount of solid waste ending up at landfill in favor to integrated solid waste management systems ending up in incineration. Measures were introduced to reduce the toxic substances in solid waste and a ban on import; manufacturing and selling of mercury thermometers were introduced in 19931994, which was a dominating source to mercury in waste in Sweden in the late 1980s. Since 1994 all MSW have to be sorted before final treatment and higher number of different sorting schemes were introduced to increase the recycling and reuse. The producer responsibility was introduced which in principle referred to a system where producers must ensure that waste from their companies is collected and recycled in the best available way.

The eco-efficiency concept was also introduced which referred to an environment-oriented policy that aims to prevent and reduce the negative impact products have on the environment and on human health throughout its entire life cycle. The idea was also to improve the waste fuel quality ending up in incineration at the same time the incineration technique was improved as well as flue gas treatment. When the EU Council Directive 99/31/EC of 1999 which later was followed late by 2008/98/EC of 2008 regarding landfilling EU-countries were obligated to reduce biological degradable waste ending up at landfills. This was favoring incineration and great numbers of incinerators were constructed and the number increased with over $60 \%$ during a 15 years period. During this period the need of temporary storages for waste fuels increased and the risks for fires by self-ignition also rose during the period 2000-2008 because there was not an incineration capacity big enough among the incinerators available at that time.

There are 70-80 fires per year in the size range of 500-2000 $\mathrm{m}^{2}$ at temporary storage sites in Sweden according to the Swedish Rescue Service Agency (SRSA). Ibrahim, 2014 found that the frequency of fire incidents at temporary storage sites has increased during recent years and 
may further increase in the future due to more waste separation and growing need of temporary storage sites. In total 217 fire incidents were recorded during the period 2000-2010 to a cumulative loss of about 49 million SEK. For future the authorities need to concern more about these fires which generate a rest fraction consisting of partly burnt material and ash that need properly handling because of its toxicity. It has been common that this type of materials are landfilled. Ashes and slag from incineration, sludge from waste water treatment, harbor and road sediments, soil fractions from landfill mining and soil remediation and others need temporary storage for longer and shorter periods. Therefore there is a need to change the definition of Landfilling in the EU-Directive making it possible for temporary storage of valuable metals, nutrients and other valuable materials for longer periods waiting economic and environmentally correct methods to be developed which might take another 30 years or more.

However, the large volumes material for recovery is stocked in the buildings and infrastructures, sewage and clean water systems in the society. The entire urban area has in many occasions been considered as landfill with a huge mixture of materials and chemical compounds. The fact is that the knowledge of amount of different materials and compounds in a city often is less than the knowledge of the content of in different landfill cells at the landfill site. In the zero waste and beyond the zero waste perspective the goal must be in efficient and economical way recovery all these materials mentioned become resource for others and coming generations to use. The recovery and recycling must be carried out in such a way that the anthropogenic loops interfere with the sustainable natural cycles so emission to air, earth and waters will be as close to zero as possible.

\section{METALS RECOVERY}

Once one of the main focuses in this paper is to raise awareness regarding metals extraction from fine-grained fractions, a literature survey on metals extraction has been therefore carried out. It can be observed nowadays that a number of physical, chemical and hybrid techniques to extract metals from solid phase is available in the scientific literature (Vandevivere et al, 2001; Andreottola et al. 2010; Zhang et al. 2009; Yoo et al. 2013; Kirkelund et al. 2009). However, even though several researchers have been studying different techniques to extract/recover metals, research has been mostly conducted with artificially polluted media, which makes it difficult to predict functionality in real conditions and upscale the process. Furthermore, results obtained with the use of artificially polluted solids can be considerably different when comparing with real conditions in which contamination is usually present in a multi-element form (Vandevivere et al, 2001), mainly when dealing with complex media such as soil, slags, sewage sludge and harbor bottom sediments. Among the different techniques, Vandevivere et al. (2001) have used a strong transition metal chelant (S,S; stereoisomer of ethylenediamine disuccin) to recover $\mathrm{Pb}, \mathrm{Zn}, \mathrm{Cu}$ and $\mathrm{Cd}$ from real contaminated media whereas Andreottola et al. (2010) have studied the use of chemical oxidation, electrochemical oxidation and electrokinetics under different conditions to remediate dredged materials from Venice Lagoon. Yoo et al.(2013) focused also on dredged marine bottom sediments and the feasibility of using chemical complexation washing agents to extract metals. Studies about remediation of metals from bay sediments and the main parameters playing important roles on the process performance were conducted in laboratory by Zhang et al. (2009), in which the use of chemical complexation reagents such as ethylenediamine tetra acetic acid, disodium salt (EDTA-2Na), sodium dodecylsulphate (SDS), acetic acid (HAc), oxalic acid (H2C2O4), ammonium acetate $(\mathrm{NH} 4 \mathrm{Ac})$ and ammonium oxalate $((\mathrm{NH} 4) 2 \mathrm{C} 2 \mathrm{O} 4)$ was studied. As it can be observed in the literature, there have been some investigations focused on harbor 
sediments and Kirkelund et al. (2009) studied in laboratory scale the use of electrodyalitic process as extraction strategy to tackle $\mathrm{Cu}, \mathrm{Zn}, \mathrm{Pb}$ and $\mathrm{Cd}$ strongly bound to anoxic sediments.

Several researchers have focused on the potential for extraction/removal of metals from ashes and slags generated in municipal solid waste incineration plants through different techniques including thermal and hydro-metallurgy (Kuboňová et al. 2013), dry discharge of bottom ashes followed by a series of magnets and Eddy currents (Meylan and Spoerri. 2014; Morf et al. 2013), fly ashes acid leaching (Meylan and Spoerri. 2014), multi-stage dust collection technique (Okada and Nishimoto 2013) and a novel combined approach using bioelectrochemical systems (BES) followed by electrolysis reactors (ER) (Tao et al. 2014). The application of wet high intensity magnetic separation to remove $\mathrm{As}, \mathrm{Cu}, \mathrm{Pb}$, and $\mathrm{Zn}$ from a sandy loam soil from a mining site was studied by Sierra et al. (2014). Extraction of $\mathrm{Cu}$ from artificially contaminated sediments through the use of electro kinetic process driven by a galvanic cell (Yuan et al., 2009) was also reported.

As previously shown, there are several authors that have investigated different methods to extract metals from solid phase materials. However, there is no literature and therefore a lack of knowledge when considering fine-grained fraction of an excavated landfill, bottom sediments of highly contaminated harbors and the potential of metals recovery. The ESEG group at LNU has started doing research on metals availability and composition of both bottom sediments from Oskarshamn Harbor (Fathollazadeh et al., 2014) and fine-grained fraction from Swedish and Estonian (Kaczala et al. 2014) excavated landfills. The initial results have shown that approximately $50 \%$ and $40 \%$ of excavated waste volume is below 40 $\mathrm{mm}$ and $10 \mathrm{~mm}$ respectively. Furthermore, the preliminary studies conducted by LNU have shown that metals such as copper, zinc can be abundant suggesting further studies on how to separate the right fractions of each metal and extract them.

Chemical recovery - The feasibility of extracting metals through chemical processes from multi-contaminated fine-grained fractions in landfills relies on material composition, particle size distribution and also metal concentrations. For example the implementation of hydrometallurgy can be relevant to recover metals from low-grade materials whereby dispersed metals are selectively dissolved into solution. The solubility of metals and right selection of an eluent (which can be recycled) can play important roles in the process. Nowadays, the main focus must be given on comparative studies to evaluate the feasibility of using different desorbing agents for selective recovery of metals considering for example: a) chemical leaching (cyanide leaching, halide leaching, thiourea leaching, thiosulphate leaching); b) chemical leaching involving ligands (EDTA, DTPA, NTA, Oxalate); c) chemical leaching involving acid treatment (sulphuric acid, hydrochloric acid, aquaregia, nitric acid, sodium hypochlorite). Besides chemical leaching processes, some experimental variables are important to be considered if the main objective is to gain a better understanding on how effective is a specific process to recover metals. Parameters that can be included in experimental design include: aeration, agitation speed (rotation), initial $\mathrm{pH}$ and liquid-to-solid ration considering that these variables will also indicate the economic feasibility, thus it will be of great importance considering them in the experimental procedures.

Electricity-based recovery - It has been reported in the literature different studies conducted to evaluate the feasibility of using electrochemical systems and electrolysis for metals recovery. For example, electrochemical methods have been used for the removal of different metals from wastewater due to compact size of equipment, simple operational procedures, and 
high removal efficiency (Tao et al. 2014). However the authors affirm that even though the use of electrolysis reactors to recover metals has been studied, focus has been mainly in the mechanisms of recovery rather than application into complex media such as fine-grained fractions from landfills, fly ashes and bottom sediments that are usually contaminated with a number of different metals. Therefore, the current challenges are on carrying out studies in lab- and pilot-scale using electricity-based methods and on the basis of results obtained, optimize them. Investigations can include external variables in order to get information of key parameters such as contact time; liquid-to-solid ratio (L/S), current densities, number of cell compartments, exchange membranes, voltages specifically applied to each metal. Furthermore it is important to highlight that investigations must be done in materials of different origins and properties (contaminant concentrations, water content, organic content and grain size distribution) in order to validate the results.

\section{DISCUSSION}

The "throw-away" mentality was established in Sweden during the late 1960s and the 1970s and had a fast growth in the country. There was a significant debate about how to change life style, reduce the consumption and consequently the volume of waste to be disposed. Following this concept, many young families have shifted their lives towards more ecological and environmental friendly ways of living such as living in small communities, using alternative sources of energy and eating organically grown food that was cultivated by the communities themselves. However, the parents generation could not have their lives following this eco-approach for long time, since as soon as certain jobs were obtained and positions in different companies, salaries were increased and the temptation of following the modern models of consumption and "throw-away" mentality was back. For example, during late 1970s plastic consumption had a tremendous increase resulting in much higher amounts of plastics in waste composition since plastics were seen as low value material that could be discarded without major impacts. However, as the time passed by, it was realized that there is a need to get away from the disposable product mentality and short life of goods towards more sustainable ways of living. However, even if people realized the problem they didn't changed their habits and style of living and the amount of people with high living standard are increasing in the world. More than 50 percent of the world population is today living in big cities and their habit has changed from lower consumption farmer living to something similar to what most swedes have had during the last 50 years. The throwaway society has now become global in a much higher degree. Therefore the zero waste and the beyond the zero waste concept must be developed and improved so more people can get a high material standard and it is not likely that the style of life will change significantly during the foreseeable future.

\section{ACKNOWLEDGEMENTS}

The Swedish Institute gave financial support to the most important project "Closing the Life Cycle of Landfills - Landfill Mining in the Baltic Sea Region for future" related to the beyond the zero waste concept. The European Cohesion Fund and the Estonian Environmental Investment Centre participated contributed with funds to an excavation project in Estonian gathering researchers from 7 countries. 


\section{REFERENCES}

\section{"Zero Waste International Alliance". ZWIA. 2014.}

Andreotottola G., Bonomo L., Gioannis GD., Ferrarese E., Muntoni A., Poltettini A., Pomi R., Saponaro S. (2010). Lab-scale feasibility tests for sediment treatment using different physico-chemical techniques. Journal of Soils and Sediments. 10:142-150.

Boesch ME., Vadenbo C., Saner D., Huter C., Hellweg S. (2014). An LCA model for waste incineration enhanced with new technologies for metal recovery and application to the case of Switzerland. Waste Management. 34:378-389.

Bolan N., Kunhikrishnan A., Thangarajan R., Kumpiene J., Park J., Makino T., Kirkham MB., Schecker K. (2014). Remediation of heavy metal(oid)s contaminated soils - To mobilize or immobilize? Journal of Hazardous Materials. 266:141-166.

H. Fathollahzadeh, F. Kaczala, A. Bhatnagar, W. Hogland. (2014). Speciation of Metals in Contaminated Sediments from Oskarshamn Harbor, Oskarshamn, Sweden. Environmental Science and Pollution Research. 21: 2455-2464.

Ibrahim, M., A., Thesis title: Risk of Spontaneus Fires at Temporary Storages Sites for Organic Material, Waste Fuels and Recylables - Quantification and mitigation. Faculty of Health and Life Sciences, Linnaeus University (Defended on February 28, 2014 at Dept. of Biology and Environmental Science, Linnaeus University, Sweden). ISBN: 978-91-87427-718 .

Jensen PE., Ottosen LM., Ferreira C. (2007). Electrodyalitc remediation of soil fines $(<63 \mu \mathrm{m})$ insuspension - Influence of current strength and L/S. Electrochemica Acta. 52:3412-3419.

Kaczala F, Mehdinejad H., Orupõld K., Bhatnagar A., Kriipsalu M., Hogland W. Leaching characteristics of fine fraction $(<10 \mathrm{~mm})$ from an excavated landfill: Physico-chemical characterization. Submitted.

Kirkelund GM., Ottosen LM., Villumsen A. (2009). Electrodyalitic remediation of harbor sediment in suspension - Evaluation of effects induced by changes in stirring velocity and current density on heavy metal removal and pH. Journal of Hazardous Materials. 169:685690.

Kuboňová L., Langová Š., Nowak B., Winter F. (2013). Thermal and hydrometallurgical recovery methods of heavy metals from municipal solid waste fly ash. Waste Management. 33-2322-2327.

Laurent A., Bakas I., Clavreaul J et al. (2014). Review of LCA studies of solid waste management systems Part I: Lessons learned and perspectives. Waste Management. 34:573588 .

Meylan G., Spoerri A. (2014). Eco-efficiency assessment of options for metal recovery from incineration residues: A conceptual framework. Waste Management. 34:93-100. 


\section{Linnaeus ECO-TECH'14, Kalmar, Sweden}

November 24-26, 2014

Morf LS., Gloor R., Haag O., Haupt M., Skutan S., Di Lorenzo F., Boni D. (2013). Precious metals and rare earth elements in municipal solid waste - Sources and fate in a Swiss incineration plant. Waste Management. 33-634-644.

Okada T., Nishimoto K. (2013). Separation of heavy metals from salts in multicomponent gas by a two stage dust collection technique. Journal of Hazardous Materials. 254-255:252-262.

Sierra C., Martínez-Blanco D., Blanco JA., Gallego, JR. (2014). Optimization of magnetic separation: A case study for soil washing at a heavy metals polluted site. Chemosphere. 107:290-296.

Tao H-C., Lei T., Shi G., Sun X-N., Wei X-Y, Zhang L-J., Wu W-M. (2014). Removal of heavy metals from fly ash leachate using combined bioelectrochemical systems and electrolysis. Journal of HazardousMaterials. 264:1-7.

Vandevivere P., Hammes F., Verstraete W., Feitjel T., Schowanek D. (2001). Metal dcontamination of soil, sediment and sewage sludge by means of transition metal cheland [S,S]-EDDS. Journal of Environmental Engineering. 127:802-811.

Yoo J-C., Lee C-D., Yang J-S., Baek K. (2013). Extraction characteristics of heavy metals from marine sediments. Chemical Engineering Journal. 228:688-699.

Yuan S., Wu C., Wan J., Lu X. (2009). In situ removal of copper from sediments by a galvanic cell. Journal of Environmental Management. 90:421-427.

Zhang L., Feng H., Li X. et al. (2009). Heavy metal contaminant remediation study of western Xiamen Bay sediment, China. Laboratory bench scale testing results. Journal of Hazardous Materials. 172:108-116. 